\title{
Applicability of Blockchain Technology to The Normal Accounting Cycle
}

\author{
Williams Kwasi Peprah ${ }^{1}$, Reynaldo P. Abas Jr. ${ }^{2}$ \& Akwasi Ampofo ${ }^{3}$ \\ ${ }^{1}$ Valley View University, School of Business, Oyibi, Accra, Ghana. E-mail: williams.peprah@vvu.edu.gh ORCID \\ Number: 0000-0002-6802-2586 \\ ${ }^{2}$ Adventist University of the Philippines, Department of Accountancy, College of Business. E-mail: rpabasjr@aup.edu.ph \\ ${ }^{3}$ University of Connecticut, School of Business, Accounting Department. E-mail: aaampofo@vt.edu
}

Received: November 22, 2021

Accepted: December 27, 2022

Available online: February 22, 2022

doi:10.11114/afa.v8i1.5492

URL: https://doi.org/10.11114/afa.v8i1.5492

\begin{abstract}
Blockchain technology is a distributed, unchangeable ledger that makes recording transactions and managing assets in a business network much easier and now a type of accounting software concerned with the transfer of asset ownership and the maintenance of an accurate financial ledger. Despite the numerous benefits of blockchain technology, there is no study on the applicability of blockchain technology to the normal accounting cycle in emerging economies in Africa. Thus, this paper provides general insights on how blockchain technology may be used in the normal accounting cycle in West Africa. The study adopted a qualitative research method and content analysis research design to understand the extent to which business leaders in West Africa are aware, understand, and utilize blockchain technology in the processing of accounting transactions to the preparation of financial statements. Results indicate that West African business leaders are well aware, understand and apply blockchain technology applications in the normal accounting cycle, and it provides cost savings, digital identity, and security. The study recommends further investigations into how to address scalability when dealing with recurrent and large transactions.
\end{abstract}

Keywords: Blockchain Technology, Normal Accounting Cycle, Accounting

\section{Introduction}

Blockchain technology is a distributed, unchangeable ledger that makes recording transactions and managing assets in a business network much easier and now a type of accounting software (Adams et al., 2018; Demirkan et al., 2020) concerned with the transfer of asset ownership and the maintenance of an accurate financial ledger.

Accounting is primarily concerned with the communication and measurement of accounting transactions and the analysis of such information (Dai, J., \& Vasarhelyi, 2017). A large part of the profession involves determining or quantifying property rights and obligations to allocate financial resources best. For accountants, blockchain clarifies asset ownership and the existence of obligations, and the potential for significant efficiency gains.

Despite the numerous literature about blockchain technology and its potential advantages, no study has been conducted yet on its potential applicability in the normal accounting cycle. Thus, this paper aims to provide general insights on how blockchain technology may be used in the normal accounting cycle.

According to Supriadi (2020), blockchain technology can improve the accounting profession by lowering the cost of maintaining and reconciling ledgers and ensuring perfect clarity regarding asset ownership and transaction history. Blockchain technology has the potential to assist accountants in gaining clarity over their organizations' available resources and liabilities while also freeing up time to focus on analysis, valuation and planning rather than bookkeeping (Pimentel, \& Boulianne, 2020). Blockchain technology will increase transaction-level accounting being performed but not by accountants (George \& Patatoukas, 2021). Instead, successful accountants analyze the accurate economic interpretation of blockchain records, reconciling the record with financial reality and valuation.

By removing reconciliations and providing confidence over transaction history, blockchain may also enable accounting to expand its scope, considering aspects that are currently thought too complex or unreliable to quantify, such as the worth of a company's data (Zhang et al., 2020). 
Blockchain technology can be used to automate bookkeeping and reconciling tasks. This could enhance accountants' efforts in particular areas while strengthening those focused on generating value elsewhere.

In business, particularly in accounting, the latest accounting software like SAP, Oracle, QuickBooks, Sunplus are just among the accounting information systems commonly used by most companies to process fast, convenient, and reliable financial transactions andto generate financial statements. Given the many and successive developments that occur in the information technology environment and the expansion of its use and utilization in the business environment, and the direct impact on the practice of accounting data systems need to examine the opportunity to make use of advanced technologies in the function of banking data systems, which represents the first basis in accounting work in the various sectors in which it operates (Alsaqa et al., 2019).

Meanwhile, aside from the aforementioned accounting information systems, the potential of using blockchain has become one of the major trends lately, as evidenced by several research studies (Kwilinski, 2019; Dai \& Vasarhelyi, 2017; Kokina et al., 2017). Blockchain technology has received much press coverage in the last few years (Kokina et al., 2017). Much has been said recently about Bitcoin, blockchains, and distributed ledger technologies (DLT).

Satoshi Nakamoto, the famed bitcoin developer, is credited with initiating these debates (Appelbaum \& Nehmer, 2020). Smith and Castonguay (2020) stated in their study that the potential for blockchain to be used as an accounting tool opened the door to more far- reaching implications in the areas of financial reporting, assurance, and corporate governance, extending the benefits beyond the internal control environment. Accounting and assurance are two professions in which blockchain technology can make a substantial impact and fundamentally alter current paradigms.

Blockchain technology functions, such as data integrity protection, rapid sharing of pertinent information, and programmable and automatic process controls, may assist in constructing a new accounting environment (Wei et al. 2020). This technology could potentially be utilized to give automated assurance, enhancing the agility and precision of the current auditing paradigm (Dai \& Vasarhelyi, 2017). Meanwhile, Orcutt (2018) reports that engineers recognized that blockchain might be used to track non-monetary assets. In 2013, Vitalik Buterin, then 19 years of age, founded Ethereum, a cryptocurrency that would follow financial transactions and the status of computer programs known as smart contracts.

\section{Accounting Cycle}

Ballada (2021) described an accounting cycle as a collection of successive processes or procedures to carry out the accounting process. The cycle's steps and their objectives are as follows:

1) Identifying the events that will be recorded. This tries to collect data on transactions or occurrences in general via source documents.

2) The journal is used to record transactions. This tries to document the economic impact of transactions on the firm in a journal, a format that allows transfer to the accounts.

3) The ledger is updated using journal entries. This procedure is intended to transmit data from the journal to the ledger for classification.

4) Constructing a trial balance. This section contains a listing for verifying the ledger's debits and credits are equal.

5) Worksheet preparation, including correcting entries. This simplifies the process of preparing financial statements.

6) Financial statement preparation. This knowledge is beneficial to decision-makers.

7) Journal entries for adjustments are journalized and posted. This column is used to track accruals, deferrals that have expired, estimations, and other occurrences from the worksheet.

8) Journal entries for the closing journal are journalized and posted. This results in the closure of temporary accounts and the transfer of profit to the owner's equity.

9) Preparation of a trial balance post-closing. This validates the debits and credits following the closing entries.

10) Entries in the reversing journal are journalized and posted. This simplifies the subsequent accounting period's documentation of certain routine transactions.

Throughout the preceding steps, definitions of words may be beneficial for a better understanding of the accounting cycle. Journalizing is the process of chronologically recording commercial transactions in a journal in terms of debits and credits (Ballada, 2021). This procedure initiates the process of entering transactions into the books of accounts. Meanwhile, posting is the process of transferring commercial transactions from journals to ledgers. A ledger is a record that contains a summary of all journal entries. In other words, journaling comes before posting. 


\section{Methodology}

This research was qualitative and applied content analysis techniques in looking at the applicability of blockchain technology in the normal accounting cycle. By evaluating and coding textual material, the content analysis research design is utilized to establish replicable and accurate findings (Drisko \& Maschi, 2016; Peprah et al., 2018). By assessing texts, such as documents, oral communication, and visuals, systematically from websites and books (Krippendorff, 2019).

\section{Results and Discussion}

As shown in Table 1 below, and based on the content analysis technique, the researcher summarizes the applicability of blockchain technology in the normal accounting cycle and its cost savings. The blockchain technology in the normal accounting cycle provides security to digital identity as per transaction in a way to minimize bookkeeping and reconciliation of transactions. Financial statement presentation format may be customized and integrated into the blockchain to give standard accounting reporting.

Table 1. Applicability of Blockchain Technology in the Normal Accounting Cycle

\section{Potential Benefits of Blockchain Technology}

Cost Savings/digital identity/security
Step 1.

Identification of events to be recorded

Step 2.

Cost Savings

\section{Normal Accounting Cycle}

\section{Applicability of Blockchain Technology in the} Normal Accounting Cycle

Blockchain technology can pre-program transactions to "self-execute" per an agreed contract, called smart contracts. For example, a buyer and a seller may decide on specific criteria for their business transactions that may be programmed through blockchain technology. Thus, minimizing or eliminating the efforts of the bookkeepers. Moreover, this may also reduce or eliminate the issuance of formal accountable forms like invoices, statements of accounts, which would result in money savings.

Moreover, the transaction between sellers and buyers may be guaranteed as authentic as digital identities are required to use blockchain technology. A transaction will not be added to the blockchain unless approved by all the members of the chain. Further, blockchain technology assures the security of the transactions because of the cryptographic feature, which would be very difficult to tamper with by unauthorized persons.

Blockchain technology would help the bookkeeper to save time on journalizing recurring transactions.

Thus, they may spend more time on valueadding activities like analyzing transactions, making special reports to management. Therefore for those entities, which might be employing several bookkeepers/accountants. Blockchain technology might be a cost-saving solution to process bulky and recurring transactions in a given time 
Cost Savings

Cost Savings

Cost Savings

Cost Svaings

Cost Savings

Cost Savings

Cost Savings

Cost Savings

Step 3.

Journal entries are posted to See discussions on Step 2 above. the ledger.

This step may not be necessary anymore as the transactions are done in Steps 1-3 is already validated by the members of the network/chain.

Step 4.

Preparation of a trial balance.

Step 5.

Preparation of the worksheet, including adjusting entries.

Step 6.

Preparation of financial statements.

Step 7. Adjusting journal entries are journalized and posted.

Step 8.

Closing journal entries are journalized and posted.

Step 9.

Preparation of a post-closing See discussions on Step 4 above. trial balance.

Step 10. Reversing journal entries are journalized
The main purpose of the trial balance is to check the equality of debits and credits. While every transaction is done electronically and according to sequential criteria, the trial balance may be abolished. Therefore, blockchain technology may save time and money again on preparing the trial balance.

The preparation of the worksheet may be foregone also as the trial balance in Step 4 above. However, with regard to the adjusting entries, blockchain technology can handle this task by following the usual process of recording and validating through the chain.

This task may be accommodated by blockchain technology by customizing the formats of the financial statements required by the financial reporting framework applicable to an entity.

See discussions on Step 2 above.

See discussions on Step 2 above.

See discussions on Step 2 above.

\section{Conclusion and Recommendations}

Organizations may examine the possible benefits of adopting blockchain technology in terms of cost savings, digital identity, and security, particularly in this age of digitization. The prevalence of cryptocurrencies and other kinds of electronic evidence may point to the adoption of blockchain technology in the accounting industry, particularly throughout the typical accounting cycle. The study points to the fact that blockchain technology has come to reduce the normal accounting cycle required as per the accounting standards in the preparation of financial statement. Nonetheless, despite the potential benefits of blockchain technology, it is important to evaluate its drawbacks.

For bookkeepers or accountants to use blockchain technology in their current and future jobs, they must understand its technicalities. To comprehend the basic technological requirements for using blockchain technology, certain skills of computing must be established. Another issue to overcome is blockchain technology's scalability when dealing with recurrent and large transactions.

The data's reliability must be maintained at all times and closely monitored by technical personnel who are directly involved in blockchain technology's upkeep. Finally, more research on the implications of blockchain technology in the 
normal accounting cycle, particularly in steps $4-10$, is strongly recommended, given that the existing literature and studies focus solely on the distributed ledger implications of blockchain technology.

\section{Reference}

Adams, R., Kewell, B., \& Parry, G. (2018). Blockchain for good? Digital ledger technology and sustainable development goals. In Handbook of sustainability and social science research (pp. 127-140). Springer, Cham.

Alsaqa, Z. H., Hussein A. I., and Mahmood, S. M. (2019). The Impact of Blockchain on Accounting Information Systems. Journal of Information Technology Management. DOI: 10.22059/jitm.2019.74301

Appelbaum, D. \& Nehmer, R. A. (2020). Auditing Cloud-Based Blockchain Accounting Systems. Journal of Information Systems. (34), 2. DOI: 10.2308/isys-52660.

Ballada, W. and Ballada S. (2021). Basic Financial Accounting and Reporting. DomDane Publishers and Made Easy Books.

Dai J. \& Vasarhelyi, M. A. (2017). Toward Blockchain-Based Accounting and

Assurance. Journal of Information Systems, 31(3), 5-21. https://doi.org/10.2308/isys- 51804.

Dai, J., \& Vasarhelyi, M. A. (2017). Toward blockchain-based accounting and assurance. Journal of Information Systems, $31(3), 5-21$.

Demirkan, S., Demirkan, I., \& McKee, A. (2020). Blockchain technology in the future of business cyber security and accounting. Journal of Management Analytics, 7(2), 189-208.

Drisko, J. W. \& Maschi, T. (2016). Content Analysis. Oxford University Press.

George, K., \& Patatoukas, P. N. (2021). The Blockchain Evolution and Revolution of Accounting. In Information for Efficient Decision Making: Big Data, Blockchain and Relevance (pp. 157-172).

Kokina, J., Mancha, R., \& Pachamanova, D. (2017). Blockchain: Emergent industry adoption and implications for accounting. Journal of Emerging Technologies in Accounting, 14(2), 91-100.

Krippendorff, K. (2019). Content Analysis, an introduction to its Methodology. SAGE Publications, Inc.

Kwilinski, A. (2019). Implementation of blockchain technology in accounting sphere. Academy of Accounting and Financial Studies Journal, 23, 1-6.

OrCutt, M. (2018). Block chain. MIT Technology Review, 121(3), 18-23b.

Peprah, W. K., Afriyie, A. O., Abandoh-Sam, J. A., \& Afriyie, E. O. (2018). Dollarization 2.0 a Cryptocurrency: Impact on Traditional Banks and Fiat Currency. International Journal of Academic Research in Business and Social Sciences, 8(6), 341-349.

Pimentel, E., \& Boulianne, E. (2020). Blockchain in Accounting Research and Practice: Current Trends and Future Opportunities. Accounting Perspectives, 19(4), 325-361.

Smith, S. S., \& Castonguay, J. J. (2020). Blockchain and accounting governance: Emerging issues and considerations for accounting and assurance professionals. Journal of Emerging Technologies in Accounting, 17(1), 119-131.

Supriadi, I. (2020). The Effect of Applying Blockchain to the Accounting and Auditing. Ilomata International Journal of Tax and Accounting, 1(3), 161-169.

Wei, P., Wang, D., Zhao, Y., Tyagi, S. K. S., \& Kumar, N. (2020). Blockchain data-based cloud data integrity protection mechanism. Future Generation Computer Systems, 102, 902-911.

Zhang, Y., Xiong, F., Xie, Y., Fan, X., \& Gu, H. (2020). The Impact of Artificial Intelligence and Blockchain on the Accounting Profession. IEEE Access, 8, 110461-110477.

\section{Copyrights}

Copyright for this article is retained by the author(s), with first publication rights granted to the journal.

This is an open-access article distributed under the terms and conditions of the Creative Commons Attribution license which permits unrestricted use, distribution, and reproduction in any medium, provided the original work is properly cited. 